\title{
(6) OPEN ACCESS \\ Has untargeted sexual health promotion for young people reached its limit? A quasi-experimental study
}

\author{
Lawrie Elliott, ${ }^{1}$ Marion Henderson, ${ }^{2}$ Catherine Nixon, ${ }^{2}$ Daniel Wight ${ }^{2}$
}

${ }^{1}$ School of Nursing Midwifery and Social Care, Edinburgh Napier University, Edinburgh, UK

${ }^{2}$ Children, Young People, Families and Health Programme, MRC/CSO Social and Public Health Sciences Unit, Glasgow, Scotland, UK

\section{Correspondence to} Professor Lawrie Elliott, School of Nursing Midwifery and Social Care, Edinburgh Napier University, Sighthill Campus, Edinburgh EH11 4BN, UK; I.elliott@napier.ac.uk

Accepted 18 October 2012 Published Online First 20 February 2013

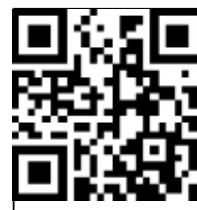

Open Access Scan to access mo free content

To cite: Elliott $\mathrm{L}$ Henderson M, Nixon C et al. J Epidemiol Community Health 2013;67:398-404.

\section{ABSTRACT}

Background Theoretically, there may be benefit in augmenting school-based sexual health education with sexual health services, but the outcomes are poorly understood. Healthy Respect 2 (HR2) combined sex education with youth-friendly sexual health services, media campaigns and branding, and encouraged joint working between health services, local government and the voluntary sector.

This study examined whether HR2: (1) improved young people's sexual health knowledge, attitudes, behaviour and use of sexual health services and (2) reduced socioeconomic inequalities in sexual health. Methods A quasi-experiment in which the intervention and comparison areas were matched for teenage pregnancy and terminations, and schools were matched by social deprivation. 5283 pupils aged $15-16$ years (2269 intervention, 3014 comparison) were recruited to cross-sectional surveys in 2007, 2008 and 2009.

Results The intervention improved males' and, to a lesser extent, females' sexual health knowledge. Males' intention to use condoms, and reported use of condoms, was unaffected, compared with a reduction in both among males in the comparison arm. Although females exposed to the intervention became less accepting of condoms, there was no change in their intention to use condoms and reported condom use. Pupils became more tolerant of sexual coercion in both the intervention and comparison arms. Attitudes towards same-sex relationships remained largely unaffected. More pupils in the $H R 2$ area used sexual health services, including those from lower socioeconomic backgrounds. This aside, sexual health inequalities remained.

Conclusions Combining school-based sex education and sexual health clinics has a limited impact. Interventions that address the upstream causes of poor sexual health, such as a detrimental sociocultural environment, represent promising alternatives. These should prioritise the most vulnerable young people.

\section{INTRODUCTION}

The poor sexual health of young people is of concern in many high-income countries because of unplanned teenage pregnancies, sexually transmitted infections, (eg, Chlamydia), and sometimes the poor quality of sexual relationships. ${ }^{1-3}$ Four recent systematic reviews assessed the impact of school-based sex education, ${ }^{45}$ and school-linked sexual health services on young people's sexual health. ${ }^{6}$ Few interventions combined both. ${ }^{7}$ Most of the studies were conducted in the USA or Canada, with some in The Netherlands, Norway, Spain and the UK. Two reviews ${ }^{5}$ focused solely on randomised controlled trials.

The findings of these reviews are equivocal. School-based sex education has a modest effect on sexual health knowledge and attitudes, but less impact on sexual behaviour. ${ }^{4}$ More specifically, Shepherd $e t a l^{5}$ suggest that policy makers and practitioners should be cautious about the impact of such programmes in bringing about behavioural change. Owen et $\mathrm{al}^{6}$ found that school-linked sexual health services do not encourage sex or risk-taking, and may at best reduce Chlamydia infection (males only) and pregnancy, however, the evidence is based on a small number of studies of variable quality. There is some evidence that combining education and contraceptive provision may reduce unintended pregnancies, but the research is insufficient to support firm recommendations. ${ }^{7}$

All four reviewers suggest that key elements, such as education and contraceptive provision could be combined to form more comprehensive interventions which would maximise the potential impact on sexual health. The theoretical assumption is that complex health issues require multisector action which provides young people with the means to reduce health risks. ${ }^{7}$ All reviewers commented on the lack of evidence of the impact of these interventions on marginalised groups.

The Scottish Government's National Sexual Health Demonstration Project, Healthy Respect, addressed each of the issues raised in these reviews. It was delivered in two phases over 8 years: Healthy Respect One (HR1) from 2001 to 2004 and Healthy Respect Two (HR2) from 2005 to March 2008. HR1 integrated education and sexual health services for young people aged 13-25 years and was supported by a communications strategy which included branding and media campaigns. HR1 improved sexual health knowledge among young people, but had little impact on attitudes or sexual risk behaviour. ${ }^{8}$ HR2 adopted the same objectives as HR1, but was more focussed. It targeted a narrower age range (10-18-year-olds), there was an explicit drive to reduce sexual health inequalities by concentrating on areas of high deprivation, and it further encouraged partnership working between the three main service sectors, namely the National Health Service, local authorities and the voluntary sector. HR2's vision was to improve young people's sexual health and respect for themselves and others, in particular their sexual partners and those with different sexual orientations. Key aims included improved sexual health knowledge and attitudes, reduced sexual risk behaviour and increased access to services. This paper contains the findings from the evaluation of $H R 2$.

\section{Research questions}

Does HR2 (1) improve young people's sexual health knowledge, attitudes, behaviour and use of sexual health services? (2) reduce socioeconomic inequalities in sexual health? 


\section{METHODS}

\section{Matching of areas and schools}

The Scottish Government had already chosen the intervention areas before the evaluation was commissioned, thus preventing a randomised control trial. Instead, we used a quasi-experimental design in which the comparison areas had teenage pregnancy and termination rates comparable with those of the interventions areas. The intervention schools had already been selected by the HR2 intervention team, and thus, were not necessarily representative of teenage pregnancy and termination rates at local authority level. Deprivation is a known indicator of early sexual debut and teenage pregnancy, ${ }^{9}$ and the schools chosen within the comparison area were thus paired with intervention schools using the percentage of free school meals (a means-tested indicator of pupil deprivation). An average difference of 3.5\% was found, with comparison schools being 3.5\% more affluent. This difference was not statistically significant. The areas were more than 40 miles apart, thus reducing the risk of contamination.

\section{Data collection}

Three cross-sectional self-completed surveys were conducted among year 4 pupils (15-16-year-olds) during the spring terms of 2007 (baseline), 2008 and 2009 (postintervention). Two postintervention surveys were conducted to increase the power to detect differences between the intervention and comparison arms. All surveys were conducted in 12 schools, six in each area. Although not reported in this paper, other components of the research evaluated the impact of HR2 on the National Health Service, local authorities (including schools), the voluntary sector, parents and also strategists across Scotland. ${ }^{10}$

\section{Participants}

A total of $5283(80 \%)$ of the 6608 registered pupils aged 1516 years were included in the analysis (figure 1 ). The remaining $20 \%$ comprised those excluded from the analysis due to missing sexual health outcome data or spoiled questionnaires $(5 \%)$, and those absent from school because they were attending college and vocational courses, sick, truanting, suspended, permanently excluded or attending alternate education settings (15\%). There were more absentees in the intervention arm than the comparison arm (19\% vs 11\%). The achieved sample included 2269 (1111 females and 1158 males) in the intervention area, and 3014 (1442 females and 1572 males) in the comparison area (figure 1). The differences in sample sizes between comparison and intervention areas largely reflected differences in school size. Totally, 1844 pupils were recruited to the first survey $(814$ intervention and 1030 comparison); 1747 to the second survey (760 intervention and 987 comparison); and 1692 to the third survey (695 intervention and 997 comparison).

\section{The interventions}

Specially trained teachers in the HR2 programme delivered a theoretically based sex education programme (SHARE). ${ }^{11}$ The average number of sessions delivered to pupils was 22, of which $33 \%$ included skills training, for instance, condom demonstration and negotiating safer sex. Sexual health services for young people were often delivered by nurses and operated either in schools or near them. The sexual health education provided in the comparison area schools consisted mainly of information giving and discussion. Teachers were not specially trained. The average number of sessions was eight and skills training was not

Figure 1 Study participants.

Intervention

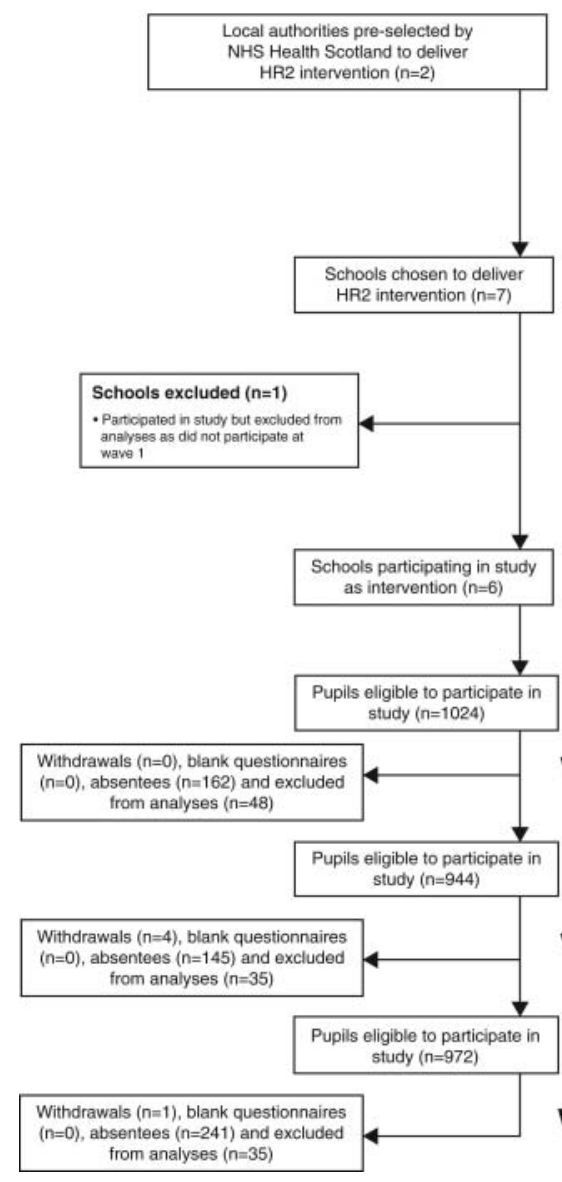

Comparison

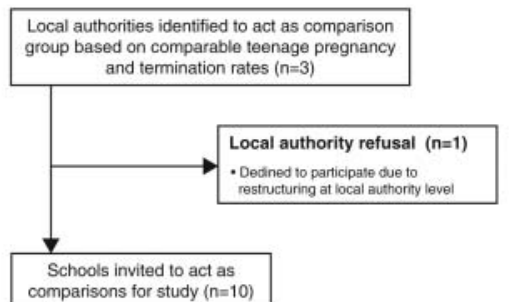
comparisons for study $(n=10)$

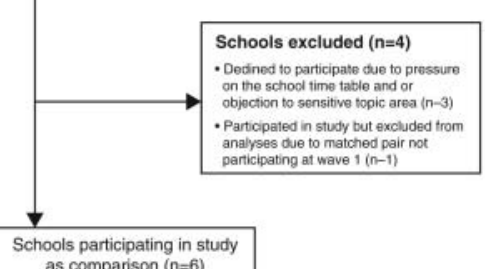

as comparison $(n=6)$

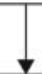

Pupils eligible to participate in study $(n=1267)$

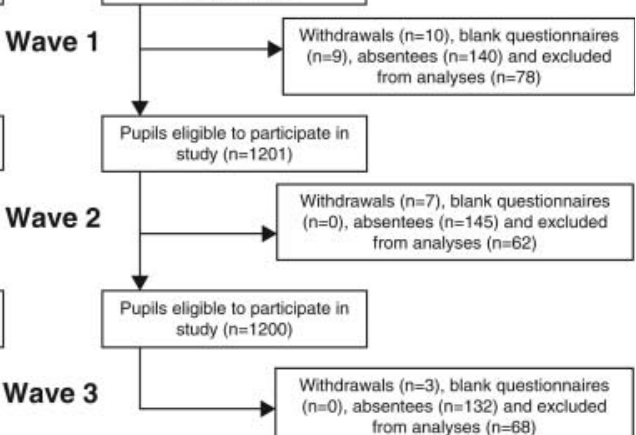


offered. Sexual health services were less available to young people and were not linked to schools. There was no overarching communications strategy.

\section{Outcome measures}

This paper focuses on sexual health knowledge, attitudes, behaviour and use of sexual health services and based on the instrument used in the SHARE trial. ${ }^{12}$ A total knowledge score compromised the sum of correct responses to 11 questions on practical sexual health information. Respondents were asked the extent to which they, their partners and their friends found condom use acceptable on a five-point scale where $1=$ 'most acceptable'. Responses were summed to give a total acceptability score. Their intention to always use condoms the next time they had sex was assessed as 'yes' or 'no'. Tolerance of same-sex relationships was based on agreement to three statements using a five-point scale where $1=$ 'most acceptable'. Responses were summed to give an overall score. Acceptability of sexual coercion was assessed by questioning their tolerance of coercion in four prespecified sexual encounters, using a five-point scale where $1=$ 'most tolerant'. Responses were summed to provide an overall score. Sexual behaviour was defined as ever having had either penetrative vaginal or anal sex. Frequency of condom use in all instances of sex was measured using a five-point scale. Responses were dichotomised between 'always or most of the time' versus 'less frequently'. Use of sexual health services in the last year was recorded as 'yes' or 'no'. The question on service use was changed in the later surveys, and thus, only postintervention data are presented. Socioeconomic status was assessed according to housing tenure, and classified as 'lower' if living in social housing, or 'higher' if living in owner occupied housing. For all variables used in adjustments, missing data was coded as missing and included within the regression models.

\section{Power calculation}

The local authority education department's anticipated school rolls suggested that the number of pupils available for each survey was 1440 for the six schools in each arm of the study. Our calculations used two-sided t tests at a 95\% level of significance and were based on data from the SHARE trial. ${ }^{12}$ In this, $81 \%$ of females and $69 \%$ of males strongly intended to use condoms the next time they had sex. We estimated the study would have $80 \%$ power to detect an increase in this outcome from $81 \%$ to $91 \%$ for females, and from $69 \%$ to $79 \%$ for males.

\section{Analysis}

Regression modelling was used to assess the differences between the intervention and comparison groups at baseline, postintervention, and over time. Due to the quasi-experimental, serial cross-sectional design, difference-in-differences (dif-in-difs) analyses were conducted using logistic and linear regression for dichotomous and continuous outcomes, respectively. Using a dif-in-difs analysis allowed us to simultaneously measure the pre- and post- within-subjects difference for the intervention and control groups. Data on the prepost within-subjects (time) and the between-subjects estimate of the intervention effect (area) is also reported to aid the interpretation of the dif-in-difs estimate. Separate analyses were conducted for gender and deprivation. All analyses were adjusted for clustering at school and pupil level through the fitting of random effects. We also adjusted for age and predictors of sexual activity, which differed significantly between the intervention and comparison arms at baseline, namely family composition, parental monitoring and religious background, which attenuated sexual experience at baseline. To account for fluctuations in pupil composition over time we also adjusted for early school leaving. All results reported are significant at $95 \%$ confidence level or higher. Unless stated otherwise, any differences between groups that are reported in the text are statistically significant. The impact of HR2 on the sexual health gap by housing tenure was assessed using data from the intervention area only.

\section{Ethical approval}

Ethical approval was granted by Edinburgh Napier University's ethics committee which conformed to the principles embodied in the Declaration of Helsinki.

\section{RESULTS}

\section{Sexual health knowledge and attitudes}

There was an increase in sexual health knowledge among males and females in the intervention arm, although the rise was more noticeable among males (table 1 ). This compared with a reduction in knowledge among both sexes in the comparison arm, particularly among females.

There was no change over time in the attitude of males in both the intervention and comparison arms towards same-sex relationships, and no difference between the groups at postintervention. By contrast, there was a reduction in the attitude of females in the comparison arm between baseline and postintervention, while the attitude of females in the intervention arm did not change over time (table 1). At baseline, most young people thought forced sex was unacceptable, however, at postintervention, there was a shift towards more tolerant attitudes among females in the intervention arm and among both sexes in the comparison arm. Females in the intervention arm held less favourable attitudes towards condoms at postintervention compared with baseline, although their attitudes at postintervention were no different to those in the comparison arm. No difference was observed in the acceptability of condom use by the males in the intervention and comparison arms at baseline and postintervention. The vast majority of pupils intended to always use condoms the next time they had sex, however, this intention weakened over time among males in the comparison arm.

\section{Sexual behaviour}

At baseline, $31 \%$ of females and $25 \%$ of males in the comparison arm, and $40 \%$ of females and $34 \%$ of males in the intervention arm reported having had sex. There was an increase, postintervention, in the number of males in the comparison arm reporting they had sex (25-31\%). There were no changes among the other groups.

At baseline, approximately two-thirds of sexually active males and females in the intervention and comparison arms reported using condoms 'always or most instances' of sex (table 2). At postintervention, males in the intervention arm maintained a higher level of reported condom use which compared with a reduction in the number of males reporting condom use in the comparison arm.

\section{Service use}

At postintervention, 55\% (377/680) of females in the intervention arm reported using sexual health services in the previous year, compared with $44 \%(386 / 886)$ in the comparison arm $(\mathrm{p}<0.05)$. A similar pattern was observed for males; $62 \%$ in the intervention arm $(429 / 698)$ compared with $39 \%$ in the comparison arm $(373 / 953)(p<0.05)$. The most common reason for using services in the intervention arm was to obtain free condoms, while in the comparison arm it was for contraceptive advice. 
Table 1 Knowledge and attitudes

\begin{tabular}{|c|c|c|c|c|c|c|c|c|}
\hline & \multicolumn{4}{|l|}{ Females } & \multicolumn{4}{|l|}{ Males } \\
\hline & Mean score & $\mathbf{n}$ & $\boldsymbol{\beta}$ (SE) & Sig. & Mean score & $\mathbf{n}$ & $\boldsymbol{\beta}$ (SE) & Sig. \\
\hline \multicolumn{9}{|l|}{ Sexual health knowledge } \\
\hline Comparison area 2007 & 7.25 & 500 & 0.00 & & 6.78 & 513 & 0.00 & \\
\hline Comparison area 2008/2009 & 6.92 & 924 & $-0.30(0.11)$ & $p<0.01$ & 6.58 & 1025 & $-0.29(0.12)$ & $\mathrm{p}<0.05$ \\
\hline Intervention area 2007 & 7.08 & 399 & 0.00 & & 6.90 & 399 & 0.00 & \\
\hline Intervention area 2008/2009 & 7.39 & 969 & $0.35(0.14)$ & $p<0.05$ & 7.18 & 739 & $0.43(0.13)$ & $\mathrm{p}<0.001$ \\
\hline Area time interaction & - & 2523 & $0.56(0.18)$ & $\mathrm{p}<0.01$ & - & 2676 & $0.72(0.18)$ & $p<0.001$ \\
\hline \multicolumn{9}{|c|}{ Acceptability of same-sex relationships } \\
\hline Comparison area 2007 & 2.94 & 488 & As 0.00 & & 3.48 & 484 & 0.00 & \\
\hline Comparison area 2008/2009 & 3.01 & 919 & $0.11(0.05)$ & $p<0.05$ & 3.51 & 1006 & $0.05(0.06)$ & n.s. \\
\hline Intervention area 2007 & 2.86 & 387 & 0.00 & & 3.29 & 386 & 0.00 & \\
\hline Intervention area 2008/2009 & 2.82 & 698 & $-0.04(0.05)$ & n.s. & 3.34 & 719 & $0.04(0.06)$ & n.s. \\
\hline Area time interaction & - & 2143 & $-0.15(0.07)$ & $p<0.05$ & - & 2186 & $0.00(0.09)$ & n.s. \\
\hline \multicolumn{9}{|l|}{ Tolerance of sexual coercion } \\
\hline Comparison area 2007 & 3.98 & 487 & 0.00 & & 3.80 & 491 & 0.00 & \\
\hline Comparison area $2008 / 2009$ & 3.82 & 916 & $-0.20(0.06)$ & $p<0.01$ & 3.60 & 1013 & $-0.21(0.06)$ & $p<0.01$ \\
\hline Intervention area 2007 & 3.91 & 387 & 0.00 & & 3.68 & 386 & 0.00 & \\
\hline Intervention area 2008/2009 & 3.75 & 689 & $-0.17(0.06)$ & $\mathrm{p}<0.01$ & 3.64 & 725 & $-0.08(0.06)$ & n.s. \\
\hline Area time interaction & - & 2129 & $-0.03(0.13)$ & n.s. & & 2207 & $0.11(0.09)$ & n.s. \\
\hline \multicolumn{9}{|l|}{ Acceptability of condom use } \\
\hline Comparison area 2007 & 1.99 & 493 & 0.00 & & 2.15 & 505 & 0.00 & \\
\hline Comparison area 2008/2009 & 2.04 & 924 & $0.05(0.04)$ & n.s. & 2.12 & 1025 & $-0.01(0.04)$ & n.s. \\
\hline Intervention area 2007 & 1.92 & 396 & 0.00 & & 2.16 & 391 & 0.00 & \\
\hline Intervention area $2008 / 2009$ & 2.04 & 697 & $0.15(0.04)$ & $p<0.01$ & 2.13 & 733 & $0.01(0.04)$ & n.s. \\
\hline \multirow[t]{2}{*}{ Area time interaction } & - & 2153 & $0.11(0.06)$ & $p<0.01$ & - & 2230 & $0.01(0.06)$ & n.s. \\
\hline & $\%$ & $n$ & OR $(95 \% \mathrm{Cl})$ & Sig. & $\%$ & $\mathrm{n}$ & OR $(95 \% \mathrm{Cl})$ & Sig. \\
\hline \multicolumn{9}{|l|}{ Intends to use condoms } \\
\hline Comparison area 2007 & 86.0 & 492 & & & 81.8 & 500 & & \\
\hline Comparison area $2008 / 2009$ & 83.1 & 912 & 0.85 (0.60 to 1.19$)$ & n.s. & 76.5 & 1014 & $0.69(0.51$ to 0.95$)$ & $\mathrm{p}<0.05$ \\
\hline Intervention area 2007 & 87.5 & 393 & & & 81.7 & 388 & & \\
\hline Intervention area $2008 / 2009$ & 85.2 & 689 & $0.99(0.87$ to 1.13$)$ & n.s. & 82.5 & 727 & $1.00(0.69$ to 1.45$)$ & n.s. \\
\hline Area time interaction & $\mathrm{n} / \mathrm{a}$ & 2486 & $1.09(0.64$ to 1.86$)$ & n.s. & $\mathrm{n} / \mathrm{a}$ & 2629 & $1.44(0.89$ to 2.32$)$ & n.s. \\
\hline
\end{tabular}

\section{Socioeconomic differences in outcomes in the intervention} area

Sexual health knowledge and attitudes

There was no difference in females' mean knowledge scores between socioeconomic groups at baseline (table 3). However, at postintervention, females from the higher socioeconomic group had better knowledge than females from the lower socioeconomic group. Males from the lower socioeconomic group were less knowledgeable than males from the higher socioeconomic group at baseline, but at postintervention, the difference was not statistically significant.

For males, there was no difference in acceptability of condoms between the lower and higher socioeconomic group at baseline and postintervention (table 3). For females, there was no

Table 2 Sexual Behaviour

\begin{tabular}{|c|c|c|c|c|c|c|c|c|}
\hline & \multicolumn{4}{|c|}{ Females } & \multicolumn{4}{|c|}{ Males } \\
\hline & $\%$ & n & OR $(95 \% \mathrm{Cl})$ & Sig. & $\%$ & n & OR $(95 \% \mathrm{Cl})$ & Sig. \\
\hline \multicolumn{9}{|l|}{ Has had penetrative sex } \\
\hline Comparison area 2007 & 31.4 & 477 & 1.00 & & 25.1 & 474 & 1.00 & \\
\hline Comparison area $2008 / 2009$ & 32.8 & 906 & 1.05 (0.81 to 1.38 ) & n.s. & 31.2 & 983 & 1.51 (1.08 to 2.09$)$ & $\mathrm{p}<0.05$ \\
\hline Intervention area 2007 & 40.2 & 383 & 1.00 & & 33.8 & 379 & 1.00 & \\
\hline Intervention area 2008/2009 & 41.2 & 690 & 1.13 (0.87 to 1.46$)$ & n.s. & 37.1 & 709 & $1.26(0.96$ to 1.66$)$ & n.s. \\
\hline Area Time interaction & - & 2456 & 0.96 (0.65 to 1.42 ) & n.s. & $\mathrm{n} / \mathrm{a}$ & 2545 & $0.98(0.65$ to 1.48$)$ & n.s. \\
\hline \multicolumn{9}{|c|}{ Condom use at all/most instances of sex } \\
\hline Comparison area 2007 & 66.4 & 137 & 1.00 & & 75.0 & 100 & 1.00 & \\
\hline Comparison area $2008 / 2009$ & 58.5 & 260 & 0.78 (0.49 to 1.22 ) & n.s. & 61.1 & 252 & 0.51 (0.29 to 0.89$)$ & $p<0.05$ \\
\hline Intervention area 2007 & 70.1 & 144 & 1.00 & & 65.1 & 109 & 1.00 & \\
\hline Intervention area $2008 / 2009$ & 69.1 & 262 & $0.87(0.54$ to 1.40$)$ & n.s. & 71.6 & 229 & $1.26(0.96$ to 1.66$)$ & n.s. \\
\hline Area Time interaction & $\mathrm{n} / \mathrm{a}$ & 803 & 1.37 (0.69 to 2.71 ) & n.s. & $\mathrm{n} / \mathrm{a}$ & 690 & 2.58 (1.13 to 5.88$)$ & $\mathrm{p}<0.05$ \\
\hline
\end{tabular}


difference in attitudes towards condom use between groups at baseline, but at postintervention, females from the lower socioeconomic group held less favourable attitudes. At baseline, females from the lower socioeconomic group were less accepting of same-sex relationships, and this difference remained at postintervention. There was no difference between males at baseline, however, at postintervention, males in the more affluent group were less accepting of same-sex relationships. There were no differences in attitude towards sexual coercion at baseline between lower and higher socioeconomic groups, and this remained at postintervention.

\section{Sexual behaviour}

More males from the lower socioeconomic group reported having sex compared with those from the higher socioeconomic group, although this difference was not statistically significant at baseline or postintervention (table 4). There was no difference in the proportion of females from different socioeconomic groups reporting penetrative sex, at baseline. However, at postintervention, more females (48\%) from the lower socioeconomic group reported having penetrative sex compared with $38 \%$ of females from the higher socioeconomic group.

At baseline, there was no difference across the socioeconomic groups in the number of females who reported using condoms at all/most instances of sex. However, at postintervention, fewer females from lower socioeconomic groups reported using condoms compared with females from higher socioeconomic groups. There was no difference in the proportion of males in both groups reporting condom use at baseline and postintervention.

\section{Service use}

At postintervention, 63\% (121/193) of females from the lower socioeconomic group used sexual health services in the last year compared with 52\% (222/431) from the higher socioeconomic group $(\mathrm{p}<0.05)$. Also, 68\% $(120 / 176)$ of males from the lower socioeconomic group used sexual health services in the last year compared with 59\% (285/485) from the higher socioeconomic group $(\mathrm{P}<0.05)$.

\section{DISCUSSION}

HR2 improved males' and, to a lesser extent, females' sexual health knowledge. Males' intended use of condoms, and reported overall use of condoms were maintained, which compared favourably with reductions in both among males in the comparison arm. Females in the intervention area became less accepting of condoms. There was no change among females in the intervention and comparison arms in their reported intention to use and overall use of condoms. There was no improvement in males' and females' attitudes to same-sex relationships, however, the attitudes of females in the comparison arm deteriorated. There was also evidence that coercive sex became more acceptable among females in the intervention arm and both sexes in the comparison arm. There was markedly higher use of sexual health services in the intervention arm by both sexes, with many more males using services in the intervention than the comparison arm. Both males and females from lower socioeconomic backgrounds also made greater use of sexual health services compared with those from higher socioeconomic groups. This aside, sexual health inequalities remained, particularly for females from lower socioeconomic backgrounds.

Our study may be limited by its design. The intervention areas were decided before the Scottish Government commissioned the evaluation, therefore preventing a randomised controlled trial. We chose a quasi-experiment in which the intervention and comparison areas were matched for teenage pregnancy and terminations, and schools were matched by social deprivation. In addition, a cohort study was not feasible

Table 3 Socioeconomic status and sexual health knowledge and attitudes (intervention group only)

\begin{tabular}{|c|c|c|c|c|c|c|c|c|}
\hline & \multicolumn{4}{|l|}{ Females } & \multicolumn{4}{|l|}{ Males } \\
\hline & Mean score & $\mathbf{n}$ & $\beta(S E)$ & Sig. & Mean score & $\mathbf{n}$ & $\boldsymbol{\beta}$ (SE) & Sig. \\
\hline \multicolumn{9}{|l|}{ Sexual health knowledge } \\
\hline Deprived pupils 2007 & 7.18 & 114 & 0.00 & & 6.40 & 114 & 0.00 & \\
\hline Affluent pupils 2007 & 7.26 & 267 & $0.07(0.26)$ & n.s. & 7.00 & 244 & $0.60(0.24)$ & $p<0.05$ \\
\hline Deprived pupils 2008/2009 & 6.97 & 200 & 0.00 & & 6.98 & 196 & 0.00 & \\
\hline Affluent pupils 2008/2009 & 7.70 & 437 & $0.70(0.17)$ & $\mathrm{p}<0.001$ & 7.36 & 502 & $0.25(0.17)$ & n.s. \\
\hline Socioeconomic status time interaction & - & 859 & $-0.47(0.30)$ & n.s. & $\mathrm{n} / \mathrm{a}$ & 889 & $0.32(0.29)$ & n.s. \\
\hline \multicolumn{9}{|l|}{ Same-sex relationships } \\
\hline Deprived pupils 2007 & 2.99 & 110 & 0.00 & & 3.29 & 111 & 0.00 & \\
\hline Affluent pupils 2007 & 2.81 & 257 & $-0.18(0.09)$ & $\mathrm{p}<0.05$ & 3.27 & 187 & $-0.03(0.10)$ & n.s. \\
\hline Deprived pupils 2008/2009 & 2.83 & 199 & 0.00 & & 3.17 & 187 & 0.00 & \\
\hline Affluent pupils 2008/2009 & 2.78 & 440 & $0.19(0.09)$ & $p<0.05$ & 3.39 & 495 & $0.21(0.08)$ & $\mathrm{p}<0.01$ \\
\hline Socioeconomic status time interaction & - & 906 & $-0.19(0.11)$ & n.s. & - & 923 & $0.25(0.14)$ & n.s. \\
\hline \multicolumn{9}{|l|}{ Sexual coercion } \\
\hline Deprived pupils 2007 & 3.81 & 109 & 0.00 & & 3.55 & 112 & 0.00 & \\
\hline Affluent pupils 2007 & 3.97 & 258 & $-0.16(0.11)$ & n.s & 3.78 & 235 & $-0.03(0.13)$ & n.s. \\
\hline Deprived pupils 2008/2009 & 3.60 & 198 & 0.00 & & 3.57 & 188 & 0.00 & \\
\hline Affluent pupils 2008/2009 & 3.85 & 432 & $-0.14(0.09)$ & n.s. & 3.68 & 500 & $-0.05(0.09)$ & n.s. \\
\hline Socioeconomic status time interaction & - & 930 & $-0.03(0.13)$ & n.s. & - & 896 & $0.12(0.15)$ & n.s. \\
\hline \multicolumn{9}{|l|}{ Acceptability of condom use } \\
\hline Deprived pupils 2007 & 1.94 & 112 & 0.00 & & 2.24 & 114 & 0.00 & \\
\hline Affluent pupils 2007 & 1.92 & 263 & $-0.02(0.07)$ & n.s. & 2.11 & 239 & $-0.12(0.08)$ & n.s. \\
\hline Deprived pupils 2008/2009 & 2.17 & 200 & 0.00 & & 2.19 & 192 & 0.00 & \\
\hline Affluent pupils 2008/2009 & 1.99 & 438 & $0.13(0.05)$ & $p<0.01$ & 2.10 & 500 & $0.04(0.04)$ & n.s. \\
\hline Socioeconomic status time interaction & - & 910 & $-0.18(0.09)$ & $\mathrm{p}<0.05$ & - & 938 & $0.01(0.10)$ & n.s. \\
\hline
\end{tabular}


Table 4 Socioeconomic status and sexual behaviour (intervention group only)

\begin{tabular}{|c|c|c|c|c|c|c|c|c|}
\hline & \multicolumn{4}{|c|}{ Females } & \multicolumn{4}{|c|}{ Males } \\
\hline & $\%$ & $\mathbf{n}$ & OR $(95 \% \mathrm{Cl})$ & Sig. & $\%$ & $\mathbf{n}$ & OR $(95 \% \mathrm{Cl})$ & Sig. \\
\hline \multicolumn{9}{|l|}{ Has had penetrative sex } \\
\hline Deprived pupils 2007 & 44.8 & 259 & 1.00 & & 38.5 & 109 & 1.00 & \\
\hline Affluent pupils 2007 & 38.6 & 105 & 0.78 (0.49 to 1.23$)$ & n.s. & 31.2 & 231 & 0.72 (0.45 to 1.16$)$ & n.s. \\
\hline Deprived pupils 2008/2009 & 47.7 & 438 & 1.00 & & 42.3 & 182 & 1.00 & \\
\hline Affluent pupils 2008/2009 & 37.9 & 195 & $0.66(0.47$ to 0.94$)$ & $\mathrm{p}<0.05$ & 38.5 & 109 & 0.72 (0.50 to 1.03$)$ & n.s. \\
\hline Socio-economic status time interaction & - & 997 & $0.85(0.47$ to 1.62$)$ & n.s. & - & & $1.16(0.62$ to 2.17$)$ & n.s. \\
\hline \multicolumn{9}{|l|}{ Condom use at all/most instances of sex } \\
\hline Deprived pupils 2007 & 69.1 & 94 & 1.00 & & 65.7 & 35 & 1.00 & \\
\hline Affluent pupils 2007 & 69.8 & 43 & $1.01(0.86$ to 1.19$)$ & n.s. & 65.6 & 64 & 1.00 (0.42 to 2.38$)$ & n.s. \\
\hline Deprived pupils 2008/2009 & 62.7 & 83 & 1.00 & & 70.6 & 68 & 1.00 & \\
\hline Affluent pupils 2008/2009 & 75.2 & 157 & 1.89 (1.04 to 3.45$)$ & $\mathrm{p}<0.05$ & 72.3 & 155 & $0.72(0.50$ to 1.02$)$ & n.s. \\
\hline Socioeconomic status time interaction & - & 377 & $2.17(0.76$ to 6.17$)$ & n.s. & - & 322 & $0.85(0.27$ to 2.66$)$ & n.s. \\
\hline
\end{tabular}

within the time period set by the funding body, so we conducted cross-sectional surveys approximately 1 year apart. To counter this deficiency, our analysis accounted for key differences between the characteristics of the intervention and comparison samples at baseline, and combined two postintervention surveys to increase the power of the study and reduce cohort variability.

A key question is whether our design and analysis led us to misinterpret the results. There are a number of points to consider. First, the use of dif-in-difs in the analysis is not without limitations, including the potential overestimation of SEs. However, we used a clustered analysis which has the effect of shrinking the SEs, and thus, mitigates against the likelihood that significant effects were found when they did not exist. The limited impact of the intervention observed within our analyses also suggests that the results do not overinflate the odds and $\beta$ s reported.

Second, although we sampled $80 \%$ of the school-aged population, those at greater sexual risk may have been missed from the intervention arm. For instance, pupils not included comprised those attending college and vocational courses, absent due to illness and truancy, suspended, permanently excluded from education, or attending alternate education settings. Comparable data collected during a survey in both the intervention and comparison areas of young people attending alternate education settings demonstrates they have increased sexual health risks. ${ }^{13}$ Our findings from the wider evaluation of Healthy Respect suggest that the intervention components designed for vulnerable young people were less developed compared with those for mainstream educational settings. ${ }^{10}$ This, combined with their greater sexual health risks, indicates that should these young people have been included in the surveys it may have further depressed the intervention effects.

Third, the more rigorous the evaluation design, the less likely it is to find positive outcomes. ${ }^{14}$ However, our results are comparable with two UK-based randomised controlled trials of sexual health education: teacher-delivered SHARE ${ }^{12} 15$ and peer-led Randomised Intervention trial of PuPil-Led sex Education (RIPPLE). ${ }^{16} 17$ both of which had limited, if any, effects on sexual risk behaviour, and no effect on unintended pregnancies. Non-randomised studies yield similar findings. A before and after evaluation of the Teenage Pregnancy Strategy in England reported reduced rates of pregnancy, but increased risk behaviour. ${ }^{18}$ Finally, retrospective evaluation of Added Power And Understanding in Sex Education (APAUSE), a school-based sex education programme in England, found improved sexual health knowledge, but no reduction in sexual risks. ${ }^{19}$
A final point is that, like nearly all other robust evaluations of sex education, this one compared an improved programme with existing provision, rather than with nothing at all. The disappointing results of this study cannot, therefore, be taken to mean that sex education has no benefits at all, only that further improvement has little extra benefit.

Theoretically, HR2 should have had a greater impact than those programmes cited above. It was guided by evidence-based recommendations and represented the culmination of 8 years of service redesign and implementation which combined sex education and sexual health services to reduce risk. ${ }^{7}$ Our results suggest it may have improved access to sexual services, including free condoms, and this may be due to the long period of sexual health service development in the intervention area. It is also possible that the increased use of these services was linked to the raised level of sexual activity among young people in the intervention area, including those from the lower socioeconomic group. Overall, however, there was little impact on sexual health behaviour. So why such limited results?

Approximately two-thirds of sexually active young people used condoms, and there are very few teenage pregnancies per head of population in Scotland (8/1000) including the intervention area. ${ }^{10}$ This might suggest that the existing level of sexual health promotion is, by and large, working, but that a minority of young people with poor sexual outcomes may be particularly resistant to populationlevel interventions. It is therefore possible, that HR2 was unable to counter the effects of more pervasive influences which shape the sexual health of young people which include values and attitudes of family, peers, local culture and the mass media. ${ }^{20}$

There may be a case for focussing future efforts on young people who engage in sexual risk behaviours. Indeed, a recent review of the literature suggests that those at greatest risk of poorer health engage in a number of risk behaviours such as smoking, drug and alcohol use and sexual risk-taking. ${ }^{21}$ This review also highlights the differences in risks across gender and social class, and suggests there is probably the need to tailor interventions for specific groups and then evaluate them separately. The differential effects between males and females, and females across the deprivation gradient observed in our study and in a similar survey conducted within the two areas in alternative education settings ${ }^{13}$ would support this suggestion. There is, of course, a danger that targeting those most at risk would lessen the advantages of a population approach, ${ }^{22}$ however, both a targeted and population approach could operate simultaneously. ${ }^{23}$ 
There is also a balance to be struck between interventions which focus on specific health risks and those which target the factors which predispose young people to take risks. These factors lie further upstream ${ }^{21}$ and are likely to be addressed by programmes which focus on the wider aspects of young people's lives. Promising examples include the Family Nurse Partnership which aims to improve parent-child attachment while providing access to health, social and welfare services, ${ }^{24}$ and the Seattle Social Development Project designed for primary school children which aims to improve pupils' commitment to school and parent-child bonding. ${ }^{25}$ These programmes are much wider in scope than specific sexual health interventions, but their impact extends to sexual and other health risks.

We conclude that further improvements in population-based interventions, such as school-based sex education combined with sexual health services are unlikely to result in better outcomes for the minority of young people with poor sexual health. More generic interventions which aim to address the underlying causes of poor sexual health, such as inadequate parenting and detrimental social relationships, show some promise in improving a constellation of health problems. We think these should be implemented to prioritise the most vulnerable young people, and then carefully evaluated.

\section{What is already known on this topic}

Existing evidence indicates that sex education improves sexual health knowledge but has little impact on behaviours such as condom use. Recent reviews suggest there may be some benefit in augmenting school-based sex education with sexual health services. However, this recommendation is based on a small number of studies of varied quality with limited evidence of a combined effect.

\section{What this study adds}

This study rigorously evaluated a multicomponent intervention that combined theoretically based sex education with youth-friendly drop-in services, and an overarching communications strategy to improve young people's sexual health. It improved sexual health knowledge and helped males to maintain their intention to use condoms and overall condom use. However, the impact on females was limited, and there was little impact on sexual health inequalities across social class, particularly among females. Furthermore, pupils became more tolerant of sexual coercion, and attitudes towards same-sex relationships remained largely unaffected. Combining sex education and sexual health services has a limited impact on young people's sexual health. Interventions which aim to address the causes of poor sexual health should be considered. These should be adapted to prioritise the most vulnerable young people, and then carefully evaluated.

Acknowledgements We would like to acknowledge the support of Professor Gillian Raab who provided advice on the statistical analysis.

Contributors All authors contributed substantially to the paper.

Funding The study was funded by NHS Health Scotland. Role of funder: Commissioner.

Competing interest None.
Ethics approval Edinburgh Napier University's Ethics Committee.

Provenance and peer review Not commissioned; externally peer reviewed.

Open Access This is an Open Access article distributed in accordance with the Creative Commons Attribution Non Commercial (CC BY-NC 3.0) license, which permits others to distribute, remix, adapt, build upon this work non-commercially, and license their derivative works on different terms, provided the original work is properly cited and the use is non-commercial. See: http://creativecommons.org/ licenses/by-nc/3.0/

\section{REFERENCES}

1 Koyama A, Corliss H, Santelli J. Global lessons on healthy adolescent sexual development. Curr Opin Pediatr 2009;21:444-9.

2 Gerressu M, Stephenson J. Sexual behaviour in young people. Curr Opin Infect Dis 2008;21:37-41

3 Marston C, King E. Factors that shape young people's sexual behaviour: a systematic review. Lancet 2006;368:1581-6.

4 Kirby D, Laris B, Rolleri L. Sex and HIV education programs: their impact on sexual behaviors of young people throughout the world. J Adolesecent Health 2007:40:206-17.

5 Shepherd J, Kavanagh J, Picot J, et al. The effectiveness and cost-effectiveness of behavioural interventions for the prevention of sexually transmitted infections in young people aged 13-19: a systematic review and economic evaluation. Health Technol Assess 2010;14:7.

6 Owen J, Carroll C, Cooke J, et al. School-linked sexual health services for young people (SSHYP): a survey and systematic review concerning current models, effectiveness, cost-effectiveness and research opportunities. Health Technol Assess 2010;14:30.

7 Oringanje $\mathrm{C}$, Meremikwu M, Eko $\mathrm{H}$, et al. Interventions for preventing unintended pregnancies among adolescents. Cochrane 2010;4.

8 Tucker JS, Fitzmaurice AE, Imamura M, et al. The effect of the national demonstration project Healthy Respect on teenage sexual health behaviour. Eur J Pub Health 2006;17:33-41.

9 Henderson $\mathrm{M}$, Butcher I, Wight $\mathrm{D}$, et al. What explains between-school differences in rates of sexual experience? BMC Public Health 2008;8:53.

10 Elliott L, Henderson M, Nixon C, et al. Evaluation of Healthy Respect Phase Two: Final report. Edinburgh 2010

11 Wight D, Dixon H. SHARE: the rationale, principles and content of a research based teacher-led sex education programme. Educ Health 2004;22:3-7.

12 Henderson M, Wight D, Raab GM, et al. Impact of a theoretically based sex education programme (SHARE) delivered by teachers on NHS registered conceptions and terminations: final results of cluster randomised trial. BMJ 2007;334:133-7.

13 Henderson M, Smith D, Elliott $\mathrm{L}$, et al. Vulnerable young people in alternative education settings: their sexual health needs, experience and use of sex education and sexual health services. Glasgow: MRC/CSO Social and Public Health Sciences Unit, 2011.

14 Guyatt G, DiCenso A, Farewell V, et al. Randomized trials versus observational studies in adolescent pregnancy prevention. J Clin Epidemiol 2000;53:167-74.

15 Wight $D, M$ Raab $G$, Henderson $M$, et al. Limits of teacher delivered sex education: interim behavioural outcomes from randomised trial. BMJ 2002;324:1430-5.

16 Ross D. Approaches to sex education: peer-led or teacher-led? PLoS Med 2008;5:1536-7.

17 Stephenson J, Strange V, Allen E, et al. The Long-Term Effects of a Peer-Led Sex Education Programme (RIPPLE): a cluster randomised trial in schools in England. PloS Med 2008;5:1579-90.

18 Wellings K, Wilkinson P, Grundy C, et al. Teenage pregnancy strategy evaluation final report synthesis. Department of Health, London. 2005

19 Blenkinsop S, Wade P, Benton T, et al. Evaluation of the APAUSE SRE programme. London: Teenage Pregnancy Unit, 2004:133.

20 Wight D, Stephenson J. School-based sex education: evaluating teacher-delivered (SHARE) and peer-delivered (RIPPLE) programmes. In: Baker P, Guthrie K, Hutchinson $C$, et al., eds. Teenage pregnancy and reproductive health. London: RCOG Press, 2007:263-74.

21 Jackson C, Haw S, Frank J. Interventions that address multiple risk behaviours or takea generic approach to risk in youth: an environmental scan with special reference to Scotland. Edimburgh: Scottish Collaboration for Public Health Research and Policy, 2010.

22 Rose G. Strategy of prevention: lessons from cardiovascular disease. BMJ 1981;282:1847-51.

23 Rose G. Sick Individuals and Sick Populations. Int J Epidemio/ 1985;14:32-8

24 Olds D, Henderson CR, Cole R, et al. Log-term effects of nurse home visitation on children's criminal and antisocial behaviour: 15-year follow-up of a randomised control trial. JAMA 1998;280:1238-44.

25 Lonczak H, Abbott R, Hawkins D, et al. Effects of the Seattle social development project on sexual behaviour, pregnancy, birth and sexually transmitted disease outcomes by age 21 years. Arch Pediatr Adolesc Med 2002;156:438-47. 